\title{
Portuguese-language version of the Epworth sleepiness scale: validation for use in Brazil*,**
}

\author{
Validação da escala de sonolência de Epworth \\ em português para uso no Brasil
}

\author{
Alessandra Naimaier Bertolazi, Simone Chaves Fagondes, Leonardo Santos Hoff, \\ Vinícius Dallagasperina Pedro, Sérgio Saldanha Menna Barreto, Murray W. Johns
}

\begin{abstract}
Objective: The aim of this study was to develop a Portuguese-language version of the Epworth sleepiness scale (ESS) for use in Brazil. Methods: The steps involved in creating the ESS in Brazilian Portuguese (ESS-BR) were as follows: translation; back-translation; comparison (by a committee) between the translation and the back-translation; and testing in bilingual individuals. The ESS-BR was applied to a group of patients who were submitted to overnight polysomnography in order to identify obstructive sleep apnea-hypopnea syndrome (OSAHS), insomnia and primary snoring. A control group was composed of subjects with a history of normal sleep habits, without reported snoring. Results: A total of 114 patients and 21 controls were included. The 8-item scores of the ESS-BR had an overall reliability coefficient of 0.83 . The study group was composed of 59 patients with OSAHS, 34 patients with primary snoring and 21 patients with insomnia. One-way ANOVA demonstrated significant differences in ESS-BR scores among the four diagnostic groups $(p<0.001)$. Post-hoc tests between groups showed that the ESS-BR scores of the patients with insomnia did not differ from those of the controls ( $p>0.05)$. The ESS-BR scores were significantly higher for OSAHS patients and for primary snorers than for controls $(p<0.05)$. In addition, the scores for OSAHS patients were significantly higher than were those for primary snorers $(p<0.05)$. Conclusions: The results of the present study demonstrate that the ESS-BR is a valid and reliable instrument for the assessment of daytime sleepiness, equivalent to its original version when applied to individuals who speak Brazilian Portuguese.
\end{abstract} Keywords: Validation studies; Sleep disorders; Cross-cultural comparison; Disorders of excessive somnolence.

\section{Resumo}

Objetivo: Desenvolver uma versão da escala de sonolência de Epworth (ESE) para o português para uso no Brasil. Métodos: A versão no português do Brasil (ESE-BR) foi desenvolvida de acordo com as seguintes etapas: tradução; retrotradução; comparação entre a tradução e a retrotradução (por um comitê); e aplicação em indivíduos bilíngues. A ESE-BR foi aplicada a um grupo de pacientes submetidos à polissonografia de noite inteira para identificar síndrome da apneia-hipopneia obstrutiva do sono (SAHOS), insônia e ronco primário. Um grupo controle foi composto de indivíduos com história de hábitos normais de sono, sem ronco aparente. Resultados: Um total de 114 pacientes e 21 controles foram incluídos. Os 8 itens do ESE-BR tiveram um coeficiente de confiabilidade total de 0,83. 0 grupo em estudo foi composto por 59 pacientes com SAHOS, 34 pacientes com ronco primário e 21 pacientes com insônia. One-way ANOVA demonstrou diferenças significativas nos escores do ESE-BR entre os quatro grupos diagnósticos $(p<0,001)$. Testes post hoc entre grupos pareados mostraram que os escores do ESE-BR para insones não diferiram daqueles dos controles $(p>0,05)$. Os escores dos pacientes com SAHOS e nos roncadores primários foram significativamente maiores que os dos controles $(p<0,05)$. Além disso, os escores para pacientes com SAHOS foram significativamente maiores do que os daqueles com ronco primário $(p<0,05)$. Conclusões: Os resultados do presente estudo demonstraram que a ESE-BR é um instrumento válido e confiável para a avaliação da sonolência diurna e equivalente a sua versão original, quando aplicada em indivíduos que falam português do Brasil

Descritores: Estudos de validação; Transtornos do sono; Comparação transcultural; Distúrbios do sono por sonolência excessiva.

\footnotetext{
* Study carried out in the Sleep Laboratory of the Universidade Federal do Rio Grande do Sul - UFRGS, Federal University of Rio Grande do Sul - School of Medicine Hospital de Clínicas de Porto Alegre - HCPA - Porto Alegre, Brazil.

Correspondence to: Alessandra N. Bertolazi. Rua Otávio Alves de Oliveira, 330/402, CEP 97050-550, Santa Maria, RS, Brasil.

Tel 5555 3222-5599. E-mail: alessa.bertolazzi@terra.com.br

Financial support: This study received financial support from the Fundo de Incentivo à Pesquisa e Eventos (FIPE, Research Incentive Fund) of the Porto Alegre Hospital de Clínicas.

Submitted: 9 December 2008. Accepted, after review: 19 May 2009.

** A versão completa em português deste artigo está disponível em www.jornaldepneumologia.com.br
} 


\section{Introduction}

Excessive daytime sleepiness (EDS) is defined as an increased propensity to fall asleep under circumstances that the affected individual and others would consider inappropriate. It has been reported that EDS affects 0.5-14\% of the population, ${ }^{(1-4)}$ seriously interfering with professional activities, as well as with family and social relationships, and reducing cognitive performance, thereby increasing the risk of accidents in the workplace and traffic accidents. ${ }^{(5-8)}$ It has been demonstrated that individuals who are sleep-deprived, due to limitations in either the quantity or quality of sleep, often are unable to respond rapidly to external stimuli and have greater difficulty in concentrating, which impairs their ability to perform certain activities, including driving a vehicle..$^{(5,9-11)}$ There is evidence that EDS is closely correlated with traffic accidents. The proportion of such accidents that can be ascribed to EDS ranges from 1\% to 3\% in the United States and is 33\% in Australia. ${ }^{(9)}$ There is a lack of statistical data linking EDS to traffic accidents in Brazil. The impact of EDS on the working adult manifests as decreased productivity, increased absenteeism, higher accident rates and a greater likelihood of disability due to EDS-related illness. The costs associated with EDS can be direct (charges for medical care or self-treatment that are borne by the patient, government, organized health care providers or insurance companies), indirect (patientand employer-borne costs that result from EDS-related morbidity and mortality) or related (costs that do not qualify as direct or indirect costs but that can be rationally associated with the illness, such as cost of property damage or injury to other parties resulting from accidents associated with the disorder).(12) The annual cost of accidents attributed to sleep disorders is estimated to be between $\$ 43.15$ billion and $\$ 56.02$ billion in the United States. Work-related accidents caused by sleepiness accounted for $\$ 24.7$ billion of those costs. ${ }^{(13-15)}$

Subjective and objective measures, as well as clinical assessments, can be used to investigate EDS. Polysomnography, the multiple sleep latency test and the maintenance of wakefulness test are the principal diagnostic tools currently available. ${ }^{(8,16-18)}$ The multiple sleep latency test was developed to assess physiologic sleep tendency or the volition to sleep in an environ- ment free of alerting factors: while patients are monitored using electroencephalography (EEG), they are given the opportunity to fall asleep during a 20-min period, four to six times a day. The maintenance of wakefulness test is a polysomnographic assessment of the propensity to remain awake during the day. However, both of these tests have the drawbacks that they must be conducted in a sleep laboratory, require qualified technicians, are time-consuming and are costly. Among the subjective instruments, the Stanford sleepiness scale and the Karolinska sleepiness scale have been employed to evaluate sleepiness. ${ }^{(8)}$ Measures of sleepiness over time include the sleep-wake activity inventory, the index of daytime sleepiness of the survey screen for sleep apnea, the Rotterdam daytime sleepiness scale and the Epworth sleepiness scale (ESS). The ESS was devised based on observations regarding the nature and occurrence of daytime sleepiness. ${ }^{(19)}$ It is a self-report questionnaire that evaluates the probability of falling asleep in eight situations involving daily activities, some known to be highly soporific. ${ }^{(19,20)}$ The global score ranges from 0 to 24, scores higher than 10 suggesting a diagnosis of EDS. ${ }^{(20)}$ The ESS has been translated to and validated for use in several other languages, being widely used because it is simple, easy to understand and rapidly completed. The aim of the present study was to translate the ESS into Portuguese and validate it for use in Brazil.

\section{Methods}

The ESS in Brazilian Portuguese (ESS-BR) was developed in phases, as follows: translation; back-translation; committee-based comparison between the translation and the back-translation; and testing in bilingual individuals. In the translation phase, the ESS was translated into Brazilian Portuguese by two independent translators who were unaware of the study objectives. The translations were compared by the authors, and a consensus version was agreed upon. Backtranslations to English were then carried out by another two translators, neither of whom had participated in any of the previous steps. The author of the original scale evaluated the backtranslations, which were then merged into a final version to be considered.

The comparison between the original ESS and the final back-translation was made by a 
committee composed of individuals who were fluent in English and who were not involved in the present study. Each of the eight items was analyzed following the method described in the literature. ${ }^{(21)}$ Through this process, the committee approved a final version of the scale in Brazilian Portuguese, to be known as the ESS-BR (Appendix 1). In order to assess the linguistic interchangeability between the translation and the original questionnaire, we applied the two scales in a group of 14 bilingual individuals, who first completed the ESS and then, two weeks later, completed the ESS-BR. Correlations were drawn between the ESS scores and the ESS-BR scores.

Between January of 2006 and September of 2007, the ESS-BR was applied in patients 18 to 65 years of age who were under evaluation for primary snoring, insomnia (psychophysiological or idiopathic) or obstructive sleep apnea-hypopnea syndrome (OSAHS) at the Sleep Laboratory of the Hospital de Clínicas de Porto Alegre (HCPA, Porto Alegre Hospital de Clínicas), a tertiary university hospital in the city of Porto Alegre, located in the south of Brazil. A control group was recruited from among patients attending the HCPA Outpatient Ophthalmology Clinic and from among other volunteers. None of the control subjects had any sleep complaints, and all presented normal polysomnography findings. Data related to age, gender, body mass index (BMl), neck circumference, comorbidities and use of medications were collected. All of the subjects underwent polysomnography. Patients with mental impairment were excluded, as were those who were shift workers, as well as those presenting polysomnographic findings suggestive of disorders other than OSAHS, insomnia or primary snoring. The ESS-BR was applied within the two-week period preceding the polysomnography study and again within the subsequent two-week period.

Overnight, attended in-laboratory polysomnography studies were conducted according to the manual devised by Rechtschaffen \& Kales. ${ }^{(22)}$ The sleep studies were conducted using a Neurofax system (Nihon Kohden, Tokyo, Japan), which includes EEG (channels C3/M2, C4/M1, 01/M2 and 02/M1), electrooculography (channels E2/M1 and E1/M1), electromyography (chin and anterior tibia), monitoring of nasal and oral flux (using a thermistor), pulse oximetry, threelead electrocardiography, snore recognition and body position sensing. Abdominal and thoracic movements were recorded using piezoelectric bands. Based on the results of the polysomnography results, the patients were categorized as belonging to one of the following groups: psychophysiological or idiopathic insomnia; primary snoring; and OSAHS. The diagnoses of OSAHS, primary snoring and insomnia were made in accordance with the international standards established by the American Academy of Sleep Medicine (AASM). ${ }^{(23)}$

Table 1 - Characteristics of the study sample.

\begin{tabular}{|c|c|c|c|c|}
\hline \multirow[t]{3}{*}{ Characteristic } & \multirow[t]{2}{*}{ Control group } & \multicolumn{3}{|c|}{ Patient groups } \\
\hline & & Insomnia & Primary snoring & OSAHS \\
\hline & $(n=21)$ & $(n=21)$ & $(n=34)$ & $(n=59)$ \\
\hline \multicolumn{5}{|l|}{ Age, years } \\
\hline Mean \pm SD & $36.1 \pm 8.0$ & $40.8 \pm 12.6$ & $43.1 \pm 12.0$ & $49.7 \pm 8.6$ \\
\hline $95 \% \mathrm{Cl}$ & $23-46$ & $18-61$ & $18-60$ & $26-60$ \\
\hline Gender, F/M & $12 / 9$ & $14 / 7$ & $26 / 8$ & $25 / 34$ \\
\hline \multicolumn{5}{|l|}{$\mathrm{BMl}, \mathrm{kg} / \mathrm{m}^{2}$} \\
\hline Mean \pm SD & $23.0 \pm 2.7$ & $24.2 \pm 2.9$ & $27.8 \pm 6.9$ & $31.3 \pm 6.8$ \\
\hline $95 \% \mathrm{Cl}$ & $18.4-29.2$ & $17.4-30.1$ & $19.5-48.1$ & $18.3-58.4$ \\
\hline \multicolumn{5}{|l|}{ AHl, number/h } \\
\hline Mean \pm SD & $0.8 \pm 0.9$ & $0.7 \pm 0.9$ & $2.2 \pm 1.4$ & $29.9 \pm 24.2$ \\
\hline $95 \% \mathrm{Cl}$ & $0.0-3.7$ & $0.0-3.7$ & $0.0-4.5$ & 5.4-104.8 \\
\hline \multicolumn{5}{|l|}{ ESS-BR score } \\
\hline Mean \pm SD & $5.2 \pm 3.0$ & $5.3 \pm 2.6^{\mathrm{a}}$ & $8.8 \pm 3.4^{b}$ & $13.5 \pm 5.1^{\mathrm{c}}$ \\
\hline
\end{tabular}


Quantitative variables were expressed as mean \pm standard deviation, and qualitative variables were expressed as percentages. When appropriate, 95\% Cls were also calculated. All statistical tests were two-tailed, and values of $p \leq 0.05$ were regarded as statistically significant. For comparisons among groups, ANOVA was performed. The effects of age, gender, BMl and apnea-hypopnea index (AHI) on the ESS-BR scores were evaluated by analysis of covariance (ANCOVA). Internal consistency of the ESS-BR was assessed using Cronbach's alpha. Data were analyzed using the Statistical Package for the Social Sciences, version 12.0 for Windows (SPSS Inc., Chicago, IL, USA). The study protocol was approved by the Research Ethics Committee of the HCPA Graduate Research Program, in accordance with national and international guidelines. All study participants gave written informed consent.

\section{Results}

There were no cultural barriers to the translation of the original ESS into Brazilian Portuguese, since the situations presented in the scale are common among Brazilians. Therefore, none of the eight items on the scale needed to be modified in terms of content.

In the group of bilingual individuals, the mean scores on the ESS-BR and original ESS were $6.7 \pm 4.1$ and $7.4 \pm 4.3$, respectively, showing good reproducibility between the translation and the original scale (intraclass correlation coefficient $=0.856 ; r=0.917 ; p<0.001)$. The internal consistency, as measured by Cronbach's alpha, was 0.76 and 0.79 , respectively, for the ESS-BR and the original ESS.

A total of 114 patients and 21 controls were included in the study. The study group was composed of 34 patients with primary snoring, 21 patients with insomnia and 59 patients with OSAHS. The characteristics of the patients and controls are listed in Table 1. The ESS-BR scores presented an overall reliability coefficient (Cronbach's alpha) of 0.83 . The mean ESS-BR score was $5.2 \pm 3.0$ for the controls, $8.8 \pm 3.4$ for the patients with primary snoring, $5.3 \pm 2.6$ for the patients with insomnia and $13.5 \pm 5.1$ for the patients with OSAHS. One-way ANOVA demonstrated significant differences among the four diagnostic groups in terms of the ESS-BR scores $(p<0.001)$. As can be seen in Figure 1 ,

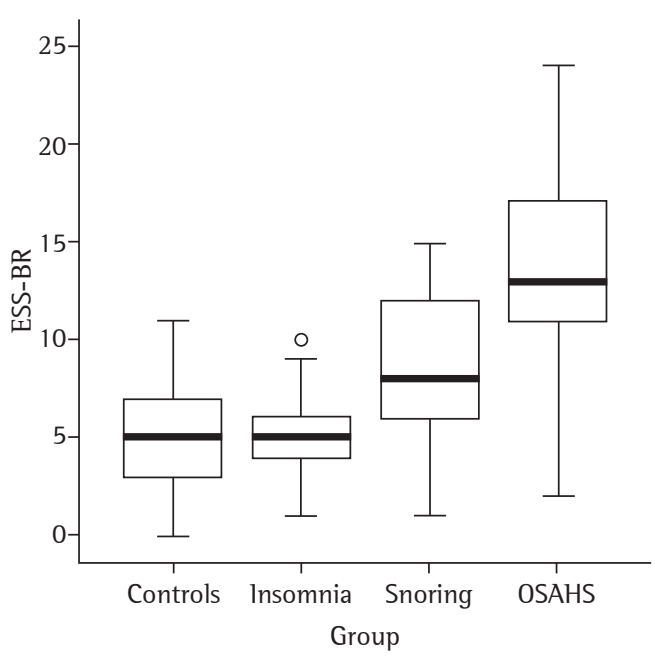

Figure 1 - Box plots showing the median, interquartile range, minimum and maximum for the ESS-BR scores, by group.

the post-hoc tests between groups showed that the ESS-BR scores for patients with insomnia did not differ from those of controls ( $p>0.05)$, whereas the scores for the patients with OSAHS and the patients with primary snoring were significantly higher than were those obtained for the controls ( $p<0.05)$, and the scores for the patients with OSAHS were significantly higher than were those obtained for the patients with primary snoring $(p<0.05)$. For the sample as a whole, a significant correlation was observed between the ESS-BR scores and the respiratory parameters obtained during polysomnography: AHI $(r=0.592 ; p<0.001)$ and lowest oxygen saturation $(r=-0.522 ; p<0.001)$.

There was a weak correlation between ESS-BR score and age $(r=0.268 ; p=0.002)$. However, when age was included as a factor in the ANCOVA, which also included gender, BMl and $A H I$, no age-related differences were found among the groups in terms of ESS-BR scores $(p<0.001)$. Patients with OSAHS were classified based on $\mathrm{AHI}$ and according to the criteria defined by the AASM. ${ }^{(23)}$ Of the 59 patients with OSAHS, 24, 14 and 21, respectively, were classified as having the mild, moderate and severe forms of the disease. The one-way ANOVA did not show statistically significant differences among the three OSAHS categories in terms of the ESS-BR score $(p=0.293)$. Considering all patients with OSAHS, the ANCOVA showed that 
there was no significant effect on the ESS-BR score in relation to age, gender, $\mathrm{BMl}$ or $\mathrm{AHl}$.

\section{Discussion}

For the 135 individuals assessed in the present study, the scores obtained on the ESS-BR showed internal consistency similar to that of translations validated elsewhere, ${ }^{(24-28)}$ despite the cultural and language differences among the populations analyzed. Comparing the ESS-BR scores obtained in the present study with those obtained in studies applying the original ESS, we found the scores to be similar for the control and OSAHS groups. In the present study, the ESS-BR scores for the insomnia group were very similar to those obtained for the control group. In another study, the ESS scores for the insomnia group were slightly lower than were those for the control group, although the difference did not quite reach statistical significance. (19) However, in the present study, there was a significant difference between the primary snoring group and the control group in terms of the ESS-BR score. The relationship between snoring and EDS has previously been suggested. (26) In the present study, this difference might be attributable due to a selection bias, since most of the patients in the primary snoring group were referred for polysomnography due to clinical suspicion of OSAHS. In addition, some of these patients might have had increased airway resistance. Furthermore, the use of a thermistor rather than a nasal cannula during polysomnography might have resulted in the underdiagnosis of respiratory disorders in the primary snoring group patients.

The correlation between $\mathrm{AHI}$ and ESS-BR score was statistically significant, as has been demonstrated in other validation studies. ${ }^{(25-28)} \mathrm{In}$ one study, ${ }^{(19)}$ the ESS scores were significantly higher for patients with severe OSAHS than for those with mild or moderate OSAHS ( $p<0.001)$, although no statistically significant difference was found between the mild and moderate forms. Unlike other validation studies, the present study evaluated only individuals submitted to polysomnography, which enhanced the stringency of the selection of the groups.

limitations of this study include the use of a thermistor rather than a nasal cannula during polysomnography, which might have resulted in the number of respiratory events being under- estimated in some patients, mainly those in the primary snoring group. Another limitation is the small number of patients of our sample, which was due to the small number of laboratory beds at our facility, as well as to budgetary restraints. Finally, the Brazilian population is quite heterogeneous. Therefore, social, cultural and economic differences among regions restrict the extent to which the ESS-BR can be applied in Brazil as a whole.

The results of the present study demonstrate that the ESS-BR is a valid and reliable instrument for the assessment of daytime sleepiness, being equivalent to its original version when applied to individuals who speak Brazilian Portuguese. Neither major cultural adaptations nor structural modifications were necessary during the validation process, despite the cultural and language differences between the two populations for which the questionnaire was validated. Therefore, the ESS-BR can be regarded as a useful tool in clinical practice and in research. Nevertheless, we believe that further adaptations or even the development of a new instrument might be necessary in order to allow the effective use of the scale at facilities in other regions of Brazil.

\section{Acknowledgments}

The authors are grateful to the technicians lara Regina Borges Kersten and Valmir Furquim Prestes, of the Sleep Laboratory of the Porto Alegre Hospital de Clínicas, for their assistance, as well as to Dr. Lúcia Campos Pellanda for her contribution in the preparation of the manuscript.

\section{References}

1. Martikainen K, Hasan J, Urponen H, Vuori I, Partinen M. Daytime sleepiness: a risk factor in community life. Acta Neurol Scand. 1992;86(4):337-41.

2. Rizzo GN. Drowsy driving in the South of Brazil. Sleep. 1999;22(Suppl 1): 304.

3. Franceschi M, Zamproni P, Crippa D, Smirne S. Excessive daytime sleepiness: a 1-year study in an unselected inpatient population. Sleep. 1982;5(3):239-47.

4. Partinen M, Rimpela M. Sleeping habits and sleep disorders in a population of 2016 Finnish adults. Yearbook Health Ed Res 1982. Helsinki: The National Board of Health 1982;26:253-260.

5. Canani SF, Menna-Barreto SS. Sonolência e acidentes automobilísticos. J Pneumol. 2001;27(2): 77-82.

6. Mulgrew AT, Ryan CF, Fleetham JA, Cheema R, Fox $\mathrm{N}$, Koehoorn M, et al. The impact of obstructive sleep 
apnea and daytime sleepiness on work limitation. Sleep Med. 2007;9(1):42-53.

7. Canani SF, John AB, Raymundi MG, Schönwald S, Menna Barreto SS. Prevalence of sleepiness in a group of Brazilian lorry drivers. Public Health. 2005;119(10):925-9.

8. Weaver TE. Outcome measurement in sleep medicine practice and research. Part 1: assessment of symptoms, subjective and objective daytime sleepiness, healthrelated quality of life and functional status. Sleep Med Rev. 2001;5(2):103-128.

9. Connor J, Norton R, Ameratunga S, Robinson E, Civil l, Dunn R, et al. Driver sleepiness and risk of serious injury to car occupants: population based case control study. BMJ. 2002;324(7346):1125.

10. Antonelli Incalzi R, Marra C, Salvigni BL, Petrone A, Gemma A, Selvaggio D, et al. Does cognitive dysfunction conform to a distinctive pattern in obstructive sleep apnea syndrome? J Sleep Res. 2004;13(1):79-86.

11. Findley LJ, Barth JT, Powers DC, Wilhoit SC, Boyd DG, Suratt PM. Cognitive impairment in patients with obstructive sleep apnea and associated hypoxemia. Chest. 1986;90(5):686-90.

12. National Commission on Sleep Disorders Research. Wake up America: a national sleep alert. Washington, D.C.: Government Printing Office, 1993.

13. George CF, Nickerson PW, Hanly PJ, Millar TW, Kryger $\mathrm{MH}$. Sleep apnoea patients have more automobile accidents. Lancet. 1987;2(8556):447. Erratum in: Lancet 1987;2(8557):524.

14. Findley LJ, Unverzagt ME, Suratt PM. Automobile accidents involving patients with obstructive sleep apnea. Am Rev Respir Dis. 1988;138(2):337-40.

15. Haraldsson PO, Carenfelt C, Tingvall C. Sleep apnea syndrome symptoms and automobile driving in a general population. J Clin Epidemiol. 1992;45(8):821-5.

16. Bittencourt LR, Silva RS, Santos RF, Pires ML, Mello MT. Excessive daytime sleepiness [Article in Portuguese]. Rev Bras Psiquiatr. 2005;27 Suppl 1:16-21.

17. Practice parameters for the indications for polysomnography and related procedures.
Polysomnography Task Force, American Sleep Disorders Association Standards of Practice Committee. Sleep. 1997;20(6):406-22.

18. Togeiro SM, Smith AK. Diagnostics methods for sleep disorders [Article in Portuguese]. Rev Bras Psiquiatr. 2005;27 Suppl 1:8-15.

19. Johns MW. A new method for measuring daytime sleepiness: the Epworth sleepiness scale. Sleep. 1991;14(6):540-5.

20. Johns MW. Sensitivity and specificity of the multiple sleep latency test (MSLT), the maintenance of wakefulness test and the Epworth sleepiness scale: failure of the MSLT as a gold standard. J Sleep Res. 2000;9(1):5-11.

21. Sperber AD. Translation and validation of study instruments for cross-cultural research. Gastroenterology. 2004;126(1 Suppl 1):S124-8.

22. Kales A, Rechtschaffen A. A manual of standardized terminology, techniques, and scoring system for sleep stages of human subjects. Los Angeles: Brain Information Service/Brain Research Institute, University of California; 1968.

23. The International Classification of Sleep Disorders: Diagnostic and Coding Manual. Westchester: American Academy of Sleep Medicine; 2005.

24. Chen NH, Johns MW, Li HY, Chu CC, Liang SC, Shu YH, et al. Validation of a Chinese version of the Epworth sleepiness scale. Qual Life Res. 2002;11(8):817-21.

25. Bloch KE, Schoch OD, Zhang JN, Russi EW. German version of the Epworth Sleepiness Scale. Respiration. 1999;66(5):440-7.

26. Chica-Urzola HL, Escobar-Córdoba F, Eslava-Schmalbach J. Validación de la escala de somnolencia de Epworth. Rev Salud Pública. 2007;9(4):558-67.

27. Izci B, Ardic S, Firat H, Sahin A, Altinors M, Karacan 1. Reliability and validity studies of the Turkish version of the Epworth Sleepiness Scale. Sleep Breath. 2008;12(2):161-8.

28. Tsara V, Serasli E, Amfilochiou A, Constantinidis T, Christaki P. Greek version of the Epworth Sleepiness Scale. Sleep Breath. 2004;8(2):91-5.

\section{About the authors}

\section{Alessandra Naimaier Bertolazi}

Physician. Santa Maria University Hospital, Federal University of Santa Maria, Santa Maria, Brazil.

\section{Simone Chaves Fagondes}

Physician. Sleep Disorders Outpatient Clinic/Sleep Laboratory of the Universidade Federal do Rio Grande do Sul - UFRGS, Federal University of Rio Grande do Sul - School of Medicine Hospital de Clínicas de Porto Alegre - HCPA - Porto Alegre, Brazil.

\section{Leonardo Santos Hoff}

Medical Student. Universidade Federal do Rio Grande do Sul - UFRGS, Federal University of Rio Grande do Sul - School of Medicine, Porto Alegre, Brazil.

\section{Vinícius Dallagasperina Pedro}

Medical Student. Federal University of Santa Maria School of Medicine, Santa Maria, Brazil.

\section{Sérgio Saldanha Menna Barreto}

Full Professor. Department of Internal Medicine, Universidade Federal do Rio Grande do Sul - UFRGS, Federal University of Rio Grande do Sul - School of Medicine, Porto Alegre, Brazil.

\section{Murray W. Johns}

Physician-in-Chief. Epworth Sleep Centre, Melbourne, Victoria, Australia. 
Appendix 1 - The Epworth sleepiness scale in Brazilian Portuguese.

\begin{tabular}{|c|c|c|c|c|}
\hline \multicolumn{5}{|c|}{ Escala de sonolência de EPWORTH (ESS-BR) } \\
\hline \multicolumn{5}{|l|}{ Nome: } \\
\hline \multicolumn{5}{|l|}{ Data: } \\
\hline \multicolumn{5}{|c|}{$\begin{array}{l}\text { Qual a probabilidade de você cochilar ou dormir, e não apenas se sentir cansado, nas seguintes situações? } \\
\text { Considere o modo de vida que você tem levado recentemente. Mesmo que você não tenha feito algumas destas } \\
\text { coisas recentemente, tente imaginar como elas o afetariam. Escolha o número mais apropriado para responder } \\
\text { cada questão. }\end{array}$} \\
\hline \multicolumn{5}{|l|}{$0=$ nunca cochilaria } \\
\hline \multicolumn{5}{|l|}{$1=$ pequena probabilidade de cochilar } \\
\hline \multicolumn{5}{|l|}{$2=$ probabilidade média de cochilar } \\
\hline \multicolumn{5}{|l|}{$3=$ grande probabilidade de cochilar } \\
\hline \multicolumn{2}{|l|}{ Situação } & \multicolumn{3}{|c|}{ Probabilidade de cochilar } \\
\hline Sentado e lendo & 0 & 1 & 2 & 3 \\
\hline Assistindo TV & 0 & 1 & 2 & 3 \\
\hline $\begin{array}{l}\text { Sentado, quieto, em um lugar público } \\
\text { (por exemplo, em um teatro, reunião ou palestra) }\end{array}$ & 0 & 1 & 2 & 3 \\
\hline Andando de carro por uma hora sem parar, como passageiro & 0 & 1 & 2 & 3 \\
\hline Sentado quieto após o almoço sem bebida de álcool & 0 & 1 & 2 & 3 \\
\hline Em um carro parado no trânsito por alguns minutos & 0 & 1 & 2 & 3 \\
\hline \multicolumn{5}{|c|}{ Obrigado por sua cooperação } \\
\hline
\end{tabular}

